\title{
Analysis of risk factors for early-onset ventilator-associated pneumonia in a neurosurgical intensive care unit
}

\author{
Guojie Teng ${ }^{1 *}$, Ning Wang ${ }^{2}$, Xiuhong Nie ${ }^{1}$, Lin Zhang ${ }^{1}$ and Hongjun Liu ${ }^{3}$
}

\begin{abstract}
Background: Ventilator-associated pneumonia (VAP) is a severe infection among patients in the neurosurgery intensive care unit (NICU).

Methods: We retrospectively evaluated risk factors for early-onset ventilator-associated pneumonia (EOVAP) from January 2019 to December 2019 at a NICU. A total of 89 NICU patients who were intubated within $48 \mathrm{~h}$ of onset and whose mechanical ventilation time was at least 7 days were enrolled. We evaluated EOVAP that occurred within the first 7 days after the onset of mechanical ventilation. The enrolled patients had no history of chronic lung disease and no clinical manifestations of infection before intubation. Clinical data of patients were recorded, and the incidence of and risk factors for EOVAP were analyzed. Patients were also grouped by age ( $\geq 65 \mathrm{vs}$. $<65$ years) and whether they had received hypothermia treatment or not.
\end{abstract}

Results: Among 89 mechanically ventilated patients (49 men and 40 women; the mean age \pm SD was $60.1 \pm 14.3$ years), 40 patients (44.9\%) developed EOVAP within 7 days and 14 patients (15.7\%) had a multidrug resistant bacterial infection. Binary logistic regression analysis indicated that older age ( $\geq 65$ years) (odds ratio [OR]:3.53, 95\% confidence interval [CI]:1.27-9.79, $\mathrm{P}=0.015)$ and therapeutic hypothermia (OR:3.68, $\mathrm{Cl}: 1.10-12.31, \mathrm{P}=0.034)$ were independent predictors of EOVAP. Levels of peripheral blood leukocytes, neutrophils and platelets were lower in the therapeutic hypothermia group than those who did not receive hypothermia treatment.

Conclusions: This study found that older age ( $\geq 65$ years) and therapeutic hypothermia were independently associated with the risk of EOVAP in NICU patients.

Keywords: Early-onset ventilator-associated pneumonia, Risk factors, Aging, Hypothermia therapy, Neurosurgical intensive care unit

\section{Background}

Ventilator-associated pneumonia (VAP) remains a common complication among neurosurgery intensive care unit (NICU) patients who require invasive mechanical ventilation. Several measures are available to decrease the

\footnotetext{
*Correspondence: tengguojie@hotmail.com

${ }^{1}$ Department of Pulmonary and Critical Care Medicine, Xuanwu Hospital Capital Medical University, No. 45 Changchun Street, Xicheng District, Beijing 10053, China

Full list of author information is available at the end of the article
}

incidence of VAP, and these include elevation of the head of the bed, maintenance of tracheal cuff pressure, spontaneous awakening trials and starting enteral nutrition as early as possible $[1,2]$. However, despite the application of these interventions, VAP is reported to affect $5-40 \%$ of patients receiving mechanical ventilation for more than 2 days[3, 4]. VAP results in markedly prolonged hospital stays[5] and increased ventilator days[6], with attributable mortality estimated to be approximately $13 \%[7]$. 
Patients with brain injury are highly susceptible to nosocomial pneumonia. Published studies have reported the incidence to range from 22 to $71 \%[8]$. Hence, there is an urgent need to prevent VAP occurrence by early identification of risk factors in patients with brain injury requiring mechanical ventilation. In this context, we aimed to evaluate risk factors for early-onset ventilatorassociated pneumonia (EOVAP) in NICU patients undergoing mechanical ventilation for at least 7 days.

\section{Methods}

\section{Study population}

This retrospective observational, single-center cohort study was conducted at Xuanwu Hospital Capital Medical University, China. Neurosurgery is a key specialty in this hospital and it has a total of 38 NICU beds. From January to December 2019, we retrospectively analyzed clinical data of all NICU patients who fulfilled the inclusion criteria. Inclusion and exclusion criteria are reported below:

\section{Inclusion criteria}

(1) Age $\geq 18$ years; (2) no fever, cough and sputum, or history of antibiotic use 1 week prior to admission; (3) patients in whom mechanical ventilation was initiated within $48 \mathrm{~h}$ of a sudden onset of cerebrovascular disease; and (4) patients with at least 7 days of mechanical ventilation time. We evaluated EOVAP that occurred from the start to the 7th day of mechanical ventilation.

\section{Exclusion criteria}

(1) Pre-existing chronic pulmonary diseases, including pneumonia, lung abscess, chronic bronchitis, chronic obstructive pulmonary disease, bronchial asthma, bronchiectasis, interstitial lung disease and pleural effusion; (2) presence of fever, cough, sputum, and prior antibiotic use; (3) chest radiograph or CT examination before admission showing atelectasis or pneumonia and (4) patients with acute and chronic liver failure, kidney failure, cancer or severe immunodeficiency[9].

\section{EOVAP definitions}

To maintain consistency with the literature, EOVAP was defined as pneumonia occurring within the first 7 days after the onset of mechanical ventilation[10-12].

VAP criteria were as follows: $[13,14]$ presence of new and/or progressive pulmonary infiltrates on a chest radiograph in a patient ventilated for more than $48 \mathrm{~h}$ plus 2 or more of the following:

(1) Temperature $>38{ }^{\circ} \mathrm{C}$; (2) leukocytosis (white blood cell count $\geq 12,000$ cells/ $\mathrm{mm} 3$ ) or leukopenia (white blood cell count $<4,000$ cells $/ \mathrm{mm} 3$ ); and (3) presence of purulent tracheal aspirate.

\section{Microbiological evaluation}

EOVAP was diagnosed by noninvasive sampling and semiquantitative culture as recommended in the guideline literature[15]. All patients who were admitted to the NICU and had been intubated received tracheobronchial aspiration (TBAS) through a closed-suction system. The TBAS was sent to the hospital's microbiology laboratories for the detection of bacteria and fungi. In the microbiology laboratory, the TBAS was plated on agar medium (3 days of culture for aerobic bacteria and 2 weeks for fungi) using a semiquantitative culture method. Bacterial identification and antibiotic susceptibility tests using standard methods were performed for samples that showed positive growth, as recommended in CDC guidelines[16]. Within $24 \mathrm{~h}$ after tracheal intubation, all patients received tracheobronchial aspiration culture and repeated aspiration culture every $48-72 \mathrm{~h}$ after that.

Multidrug-resistant (MDR) was defined as nonsusceptibility to 1 or more agents in 3 or more antimicrobial classes (ie, aminoglycosides, third-/fourth-generation cephalosporins, fluoroquinolones, beta-lactam/beta-lactamase inhibitors, and carbapenems) for Gram-negative organisms; nonsusceptibility to oxacillin and/or cefoxitin (anti-staphylococcal beta-lactams) for Gram-positive Staphylococcus aureus; and non-susceptibility to vancomycin and/or teicoplanin (glycopeptides) for Gram-positive Enterococcus spp. [17, 18].

\section{Data collection}

The following data were obtained: (1) Patient's information: age (categorized as $\geq 65$ and $<65$ years), sex, smoking, body mass index (BMI), pre-existing comorbidities (coronary artery disease, hypertension, diabetes), intubation time (hospital admission or prehospital intubation), Acute Physiology and Chronic Health Evaluation II (APACHE II) and Glasgow Coma Scale/Score(GCS); (2) laboratory data: albumin (ALB) C-reactive protein (CRP), procalcitonin (PCT), alanine aminotransferase (ALT), serum creatinine ( $\mathrm{Scr}$ ), full blood count, sputum culture and chest X-ray; (3) medications administered: norepinephrine, glucocorticoids, mannitol, therapeutic hypothermia, antibiotics administered, and sedative and analgesics after the intubation; and (4) outcomes of EOVAP and non-EOVAP groups: mechanical ventilation time, ICU stay, hospital stay, and 28-day mortality.

\section{Statistical analysis}

All statistical analyses were performed using SPSS statistical software version 19.0. Continuous data were presented as mean \pm standard deviation for normally distributed variables and median (interquartile range, IQR; 25th-75th percentile) for those not normally distributed. 
Independent-Samples T-Test or Mann-Whitney nonparametric test was used to compare differences in continuous variables depending on their distribution. Chi-square test or Fisher's Exact test was used to compare categorical data. Binary multivariable logistic regression analysis was performed for parameters with $\mathrm{p}<0.10$ on univariate analysis and the odds ratios (ORs) with $95 \%$ confidence intervals $(95 \% \mathrm{CIs})$ were calculated. All tests were two-tailed, with the significance level set at $\mathrm{p}<0.05$.

\section{Results}

\section{Patient characteristics}

During a 12-month period, 615 mechanically ventilated patients were admitted to the NICU at our hospital. After an initial medical record review, the following records were removed from the analysis: 434 records for either extubation or death within 7 days; 63 records for intubation performed more than $48 \mathrm{~h}$ after admission; and 29 records for infection, chronic lung disease, or liver and kidney failure before intubation. A total of 89 patients who underwent mechanical ventilation satisfied the inclusion criteria. Among 89 mechanically ventilated patients ( 49 men and 40 women; the mean age \pm SD was $60.1 \pm 14.3$ years), APACHE II was $13.8 \pm 3.8$ and the GCS was $7.8 \pm 2.2$. Of the 89 patients, there were 52 cases of subarachnoid hemorrhage, 29 cases of intracerebral hemorrhage, and 8 cases of massive cerebral infarction. Of the 89 patients, 40 patients (44.9\%) developed EOVAP within 7 days (Fig. 1).

\section{Antibiotic use and multidrug-resistant bacteria (MDRB)}

All 89 patients were treated with prophylactic antibiotics (including 33 cases with cefminox, 32 cases with piperacillin tazobactam and 24 cases with ceftriaxone) within $24 \mathrm{~h}$ after intubation. Antibiotics were continuously administered and adjusted according to the results of the bacterial culture. Within 7 days of intubation, 12 patients (13.5\%) received carbapenem treatment for more than 3 days, of which 3 patients had their medication adjusted based on the results of sputum culture, and 9 received empirical antibiotic escalation treatment. The sputum culture results within 7 days in 14 patients (15.7\%) showed MDRB (3 cases of Staphylococcus aureus, 3 cases of Burkholderia cepacia, 3 cases of Klebsiella pneumoniae, 3 cases of Corynebacterium striatum, 1 case of Acinetobacter pitti, 1 case of Acinetobacter beijerinckii, and 1 case of Acinetobacter baumannii). However, statistical results showed no significant correlation between the administration of carbapenem antibiotics and the appearance of Gram-negative MDRB in the short term.

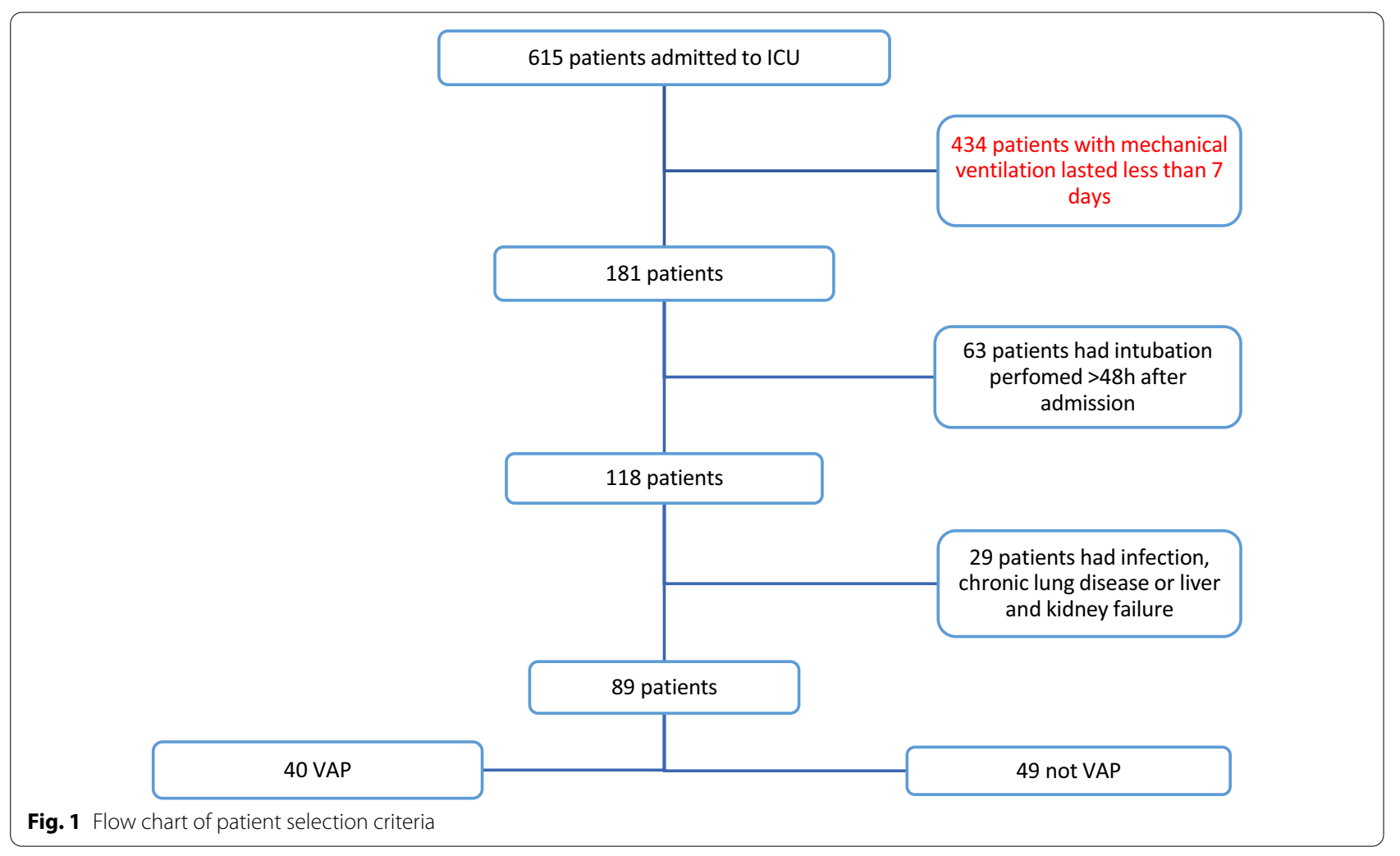




\section{Risk factors for EOVAP}

All 89 patients had no infection or underlying lung diseases on presentation. They were intubated within $48 \mathrm{~h}$ of the onset of cerebrovascular disease and mechanical ventilation was maintained for more than 7 days. All patients were placed in a position with the head of the bed raised $>30^{\circ}$ on the day of intubation which lasted for 7 days. Within 2 days after intubation, all patients were provided with gastrointestinal nutritional support, acid inhibitors ( $\mathrm{H} 2$ blocker or proton pump inhibitor), and blood glucose monitoring. Of the 89 patients, 2 underwent tracheotomy on the $5^{\text {th }}$ and $6^{\text {th }}$ days after intubation. The univariate analysis of the EOVAP group and the nonEOVAP group showed that: $\geq 65$ years old, PCT1(PCT at the time of diagnosis of pneumonia), CRP1(CRP at the time of diagnosis of pneumonia), and Platelet1(Platelet at the time of diagnosis of pneumonia) were statistically different between the groups. There were no significant differences between the two groups in the use of glucocorticoids, MDRB, and 28-day mortality, but the total mechanical time of the EOVAP group was longer than that of the non-EOVAP group (Table 1).

Five factors with $\mathrm{P}<0.1$ in the univariate analysis: $\geq 65$ years, therapeutic hypothermia, PCT1, CRP1, and Platelet1 were included in the binary multivariable logistic regression analysis. Logistic regression analyses showed that older age ( $\geq 65$ years) ((OR: $3.53, \mathrm{CI}$ : $1.27-9.79-0.738, \mathrm{p}=0.015)$ and therapeutic hypothermia (OR:3.68, CI:1.1-12.31, $\mathrm{p}=0.034$ ) were independent predictors of EOVAP (Table 2).

\section{Older age ( $\geq 65$ years) and therapeutic hypothermia}

Patients were grouped by age ( $\geq 65$ vs. $<65$ years) and whether they had received hypothermia treatment or not, and differences in clinical characteristics between these groups were compared. Underlying diseases, inflammatory indicators, drug use and mortality, were not significantly different between the two age groups. However, levels of peripheral blood leukocytes, neutrophils and platelets were lower in the therapeutic hypothermia group than the group that did not receive hypothermia treatment, with no significant differences in other indicators, including measures of inflammation and sedative use (Table 3).

\section{Discussion}

In our retrospective analysis of risk factors for EOVAP in NICU patients, the results showed that older age ( $\geq 65$ years) and therapeutic hypothermia were independent predictors of EOVAP. The levels of peripheral blood leukocytes, neutrophils, and platelets in hypothermia-treated patients were lower than those of non-hypothermia-treated patients. The platelet count in patients with therapeutic hypothermia was associated with 28-day mortality.

Even though most MDRB are isolated from patients with late-onset VAP, accumulating evidence shows that drug resistance is also a problem in patients who develop early-onset VAP $[19,20]$. In this study, NICU patients with no history of antibiotic use before admission had a $15.7 \%$ (14/89) incidence of MDRB during 7-day mechanical ventilation. Several studies have shown that the percentage of MDR pathogens among patients with early-onset VAP varied from as low as $10 \%$ to as high as $51 \%[21]$. In our study, the incidence of MDRB was only $15 \%$, which may be due to strict patient selection criteria. We excluded patients with previous underlying lung disease and liver and kidney dysfunction, as these patients are high-risk groups for MDRB. There was no correlation between the administration of carbapenem antibiotics in the short term and the emergence of Gram-negative MDRB. It is speculated that MDRB may originate from exogenous sources such as contaminated respiratory instruments, infected aerosols from the ICU environment and contaminated hands and apparel of healthcare workers[22, 23].

Although univariate analysis showed statistical differences in CRP and PCT between the EOVAP group and the non-EOVAP group, binary logistic regression indicated that CRP and PCT were not independent predictors of EOVAP, a finding consistent with other studies [29-32]. In our study, older age ( $\geq 65$ years) and hypothermia therapy were independent predictors of EOVAP. A European multicenter cohort study reported that VAP was not increased among the elderly, but the associated mortality in these patients was higher[24]. This is contrary to our findings. Our evaluation of 89 patients with no history of chronic lung disease, no infection before intubation, and a similar duration of mechanical ventilation after intubation, showed that age $\geq 65$ was an independent predictor of EOVAP. The divergent findings between the two studies may be attributed to the stringent patient inclusion criteria adopted in our study. The high incidence of EOVAP in the elderly ( $\geq 65$ years) may be due to the gradual decline in respiratory function with age, the gradual atrophy of respiratory muscles, the decline in lung elasticity and the decline in the ability to expel sputum. At the same time, the respiratory mucosa of the elderly shrinks, the mucosal function decreases, and the local defense function of the respiratory tract decreases, leading to an increase in the incidence of VAP.

Several published reports have indicated that hypothermia therapy is one of the most important risk factors for early-onset pneumonia. Esnault reported that the incidence of EOVAP after severe traumatic brain injury was more than $61 \%$ and that hypothermia was one of the 
Table 1 Characteristics of NICU patients comparing EOVAP vs. non-EOVAP groups

\begin{tabular}{|c|c|c|c|}
\hline Variables & $\operatorname{EOVAP}(n=40)$ & Non-EOVAP $(n=49)$ & $P$-value \\
\hline \multicolumn{4}{|l|}{ Patient's information } \\
\hline Ageing $(\geq 65 y)$ & 23 & 17 & 0.031 \\
\hline Male gender & 23 & 26 & 0.675 \\
\hline Smoking & 3 & 6 & 0.506 \\
\hline BMI (body mass index) & $25.4 \pm 6.0$ & $25.1 \pm 3.9$ & 0.845 \\
\hline Coronary artery & 5 & 5 & 0.997 \\
\hline Diabetes & 5 & 11 & 0.224 \\
\hline Hypertension & 24 & 26 & 0.512 \\
\hline Prehospital intubation & 2 & 5 & 0.287 \\
\hline APACHE II & $14.3 \pm 4.0$ & $13.4 \pm 3.7$ & 0.274 \\
\hline GCS & $7.8 \pm 2.0$ & $7.9 \pm 2.4$ & 0.864 \\
\hline \multicolumn{4}{|l|}{ Drug use (cumulative use time $>=3 \mathrm{~d}$ ) } \\
\hline Norepinephrine & 19 & 20 & 0.527 \\
\hline Glucocorticoid & 11 & 13 & 0.918 \\
\hline Mannitol & 34 & 43 & 0.705 \\
\hline Therapeutic hypothermia & 13 & 8 & 0.074 \\
\hline Carbapenem antibiotics & 5 & 7 & 0.806 \\
\hline Propofol or propofol medium and long chain fat emulsion & 26 & 36 & 0.387 \\
\hline Midazolam & 27 & 36 & 0.641 \\
\hline Remifentanil or fentanyl & 36 & 44 & 1.000 \\
\hline Proton pump inhibitor & 34 & 46 & 0.289 \\
\hline $\mathrm{H} 2$ receptor antagonist & 6 & 3 & 0.291 \\
\hline \multicolumn{4}{|l|}{ Laboratory testing (At the time of intubation) } \\
\hline ALB $(g / l)$ & $33.0 \pm 6.7$ & $32.5 \pm 6.7$ & 0.752 \\
\hline $\mathrm{CRP}(\mathrm{mg} / \mathrm{l})$ & $61.4 \pm 46.7$ & $60.6 \pm 47.3$ & 0.936 \\
\hline $\mathrm{PCT}(\mathrm{ng} / \mathrm{mL})$, median (IQR) & $0.220(0.10-0.5200)$ & $0.120(0.080-0.500)$ & 0.148 \\
\hline $\operatorname{ALT}(\mathrm{U} / \mathrm{I})$, median $(\mathrm{IQR})$ & $29.00(18.25-33.00)$ & $30.00(19.00-33.5)$ & 0.944 \\
\hline $\operatorname{Scr}(\mathrm{mmol} / \mathrm{l})$, median $(\mathrm{IQR})$ & $65.50(51.25-83.00)$ & $58.00(43.00-81.00)$ & 0.180 \\
\hline White blood cell count $\left(\times 10^{9} / /\right)$ & $13.4 \pm 5.0$ & $12.5 \pm 3.8$ & 0.317 \\
\hline Neutrophils $\left(\times 10^{9} / \mathrm{l}\right)$ & $11.9 \pm 4.7$ & $12.6 \pm 12.2$ & 0.734 \\
\hline Lymphocyte $\left(\times 10^{9} / \mathrm{l}\right)$ & $0.95 \pm 0.46$ & $0.87 \pm 0.38$ & 0.373 \\
\hline Platelet $\left(\times 10^{9} / \mathrm{l}\right)$ & $180.9 \pm 66.5$ & $175.3 \pm 61.7$ & 0.683 \\
\hline \multicolumn{4}{|l|}{ Laboratory testing (on day 7 after intubation) } \\
\hline ALB $(g / l)$ & $33.8 \pm 5.1$ & $32.8 \pm 5.1$ & 0.367 \\
\hline $\operatorname{ALT}(\mathrm{U} / \mathrm{l})$, median (IQR) & $36.50(30.00-62.75)$ & $46.00(31.00-60.5)$ & 0.468 \\
\hline $\operatorname{Scr}(\mathrm{mmol} / \mathrm{I})$, median (IQR) & $63.5(45.50-93.00)$ & $52.00(42.00-76.5)$ & 0.198 \\
\hline \multicolumn{4}{|c|}{ Laboratory testing (EOVAP group: when pneumonia was diagnosed, non-EOVAP group: on day 7 after intubation) } \\
\hline $\mathrm{CRP}(\mathrm{mg} / \mathrm{l})$, median (IQR) & $76.45(53.38-111.00)$ & $55.00(30.25-64.75)$ & 0.008 \\
\hline $\mathrm{PCT}(\mathrm{ng} / \mathrm{ml})$, median (IQR) & $0.22(0.13-0.44)$ & $0.120(0.075-0.310)$ & 0.047 \\
\hline White blood cell count $\left(\times 10^{9} / \mathrm{l}\right)$ & $9.4 \pm 3.6$ & $9.7 \pm 3.2$ & 0.689 \\
\hline Neutrophils $\left(\times 10^{9} /\right)$ & $7.8 \pm 3.4$ & $7.9 \pm 3.0$ & 0.891 \\
\hline Lymph $\left(\times 10^{9} / \mathrm{I}\right)$ median $(\mathrm{IQR})$ & $0.8(0.58-1.22)$ & $0.97(0.73-1.36)$ & 0.108 \\
\hline Platelet $\left(\times 10^{9} / \mathrm{l}\right)$ & $147.4 \pm 63.4$ & $177.6 \pm 76.2$ & 0.044 \\
\hline MDRB & 7 & 7 & 0.679 \\
\hline \multicolumn{4}{|l|}{ Outcomes of EOVAP and non-EOVAP groups } \\
\hline Mechanical ventilation time (h) median (IQR) & $384(301-493)$ & $290(207-432)$ & 0.02 \\
\hline ICU stays $(d)$ & $19.4 \pm 9.6$ & $20.3 \pm 11.0$ & 0.676 \\
\hline Hospital stays (d) & $24.8 \pm 14.6$ & $23.5 \pm 11.7$ & 0.628 \\
\hline 28-day mortality (d) & 8 & 7 & 0.474 \\
\hline
\end{tabular}


Table 2 Results of binary multivariable logistic regression analysis showing risk factors for EOVAP in NICU patients

\begin{tabular}{llllll}
\hline Variable & $\boldsymbol{\beta}$ & SE & Wald value & EXP(B) (95\%Cl) & P-value \\
\hline Therapeutic hypothermia & 1.303 & 0.616 & 4.476 & $3.68(1.10-12.31)$ & $3.53(1.27-9.79)$ \\
Older age ( $\geq$ 65 years) & 1.262 & 0.520 & 5.884 & $1.01(1.00-1.01)$ & 0.034 \\
CRP1 & 0.006 & 0.004 & 1.870 & $1.04(0.66-1.53)$ & 0.171 \\
PCT1 & 0.004 & 0.216 & 0.000 & $0.998(0.99-1.01)$ & 0.944 \\
Platelet1 & -0.002 & 0.004 & 0.367 &
\end{tabular}

Table 3 Characteristics of NICU patients comparing hypothermia therapy vs. non-hypothermia therapy groups

\begin{tabular}{|c|c|c|c|}
\hline Variables & Hypothermia therapy $(n=21)$ & $\begin{array}{l}\text { Non-hypothermia therapy } \\
(\mathrm{n}=68)\end{array}$ & $P$-value \\
\hline \multicolumn{4}{|l|}{ Laboratory testing (7 days after intubation) } \\
\hline CRP (mg/l), median (IQR) & $57.53(22.10-79.20)$ & $58.76(30.57-92.35)$ & 0.565 \\
\hline $\mathrm{PCT}(\mathrm{ng} / \mathrm{ml})$, median (IQR) & $0.13(0.10-0.21)$ & $0.17(0.08-0.53)$ & 0.431 \\
\hline $\operatorname{ALT}(\mathrm{U} / \mathrm{I})$, median (IQR) & $35.43(33.13-39.61)$ & $44.50(30.00-61.75)$ & 0.889 \\
\hline $\mathrm{Scr}(\mathrm{mmol} / \mathrm{I})$, median (IQR) & $50.00(38.00-76.00)$ & $58.50(43.50-84.00)$ & 0.214 \\
\hline White blood cell count $\left(\times 10^{9} /\right)$ & $7.60 \pm 2.31$ & $10.10 \pm 3.40$ & 0.002 \\
\hline Neutrophils $\left(\times 10^{9} / \mathrm{l}\right)$ & $6.22 \pm 2.19$ & $8.34 \pm 3.04$ & 0.004 \\
\hline $\operatorname{Lymph}\left(\times 10^{9} / \mathrm{l}\right)$ & $0.86 \pm 0.48$ & $1.13 \pm 0.61$ & 0.072 \\
\hline Platelet $\left(\times 10^{9} / I\right)^{*}$ & $137.52 \pm 63.20$ & $180.60 \pm 79.59$ & 0.026 \\
\hline \multicolumn{4}{|c|}{ Use of sedative and analgesics (cumulative use time $>=3 \mathrm{~d}$ ) } \\
\hline $\begin{array}{l}\text { Propofol or propofol medium and long chain fat } \\
\text { emulsion }\end{array}$ & $13(61.9 \%)$ & $49(72.1 \%)$ & 0.376 \\
\hline Midazolam & $17(81.0 \%)$ & $46(67.6 \%)$ & 0.258 \\
\hline Remifentanil or fentanyl & $18(85.7 \%)$ & $62(91.2 \%)$ & 0.755 \\
\hline
\end{tabular}

*The platelet count (7 days after intubation): mortality group (within 28 days) vs. alive group $P=0.006$

major risk factors for EOVAP[12]. Sébastien reported that after out-of-hospital cardiac arrest, therapeutic hypothermia was associated with an increased risk of early-onset pneumonia[25]. Our findings further corroborate these observations. Hypothermia impairs immune functions by inhibiting the secretion of proinflammatory cytokines and suppressing leukocyte migration and phagocytosis [26]. Hypothermia-induced insulin resistance and hyperglycemia may further increase infection risk[25], leading to an increase in the incidence of VAP.

Bro-Jeppesen and Dufner reported that hypothermia treatment could lead to a decrease in the number of white blood cells and neutrophils[27, 28], which is consistent with the results of our study. However, the relationship between hypothermia and platelet count is controversial. Nielsen reported that thrombocytopenia occurred after therapeutic hypothermia in patients with cardiac arrest[29, 30]. But Takashi reported that therapeutic hypothermia had no significant effect on platelet counts in patients with severe traumatic brain injury. Our study found that after 7 days of mechanical ventilation, the platelet count of patients treated with hypothermia was significantly reduced, and it was associated with 28-day mortality $(P=0.006)$. The cause of thrombocytopenia due to hypothermia is still unclear. Some studies have shown that hypothermia enhances shear-induced platelet aggregation[31] and decreases platelet function[32]. These results suggest that the monitoring of platelets in patients with hypothermia is essential. Further evaluation is needed when clinicians detect thrombocytopenia in patients treated with hypothermia.

The limitations of this study deserve consideration. They include the single-center retrospective design and the small sample size; a prospective design with a larger sample would yield more robust results. Our study used the VAP definition for analysis, but the use of ventilatorrelated events may have better clinical applicability.

\section{Conclusion}

We retrospectively analyzed the clinical data of $89 \mathrm{NICU}$ patients who received mechanical ventilation between January and December 2019. All 89 patients had no infection or underlying lung diseases. Our findings showed that older age ( $\geq 65$ years) and therapeutic hypothermia 


\section{were independently associated with the risk of EOVAP in NICU patients.}

\section{Abbreviations}

VAP: Ventilator-associated pneumonia; NICU: Neurosurgery intensive care unit; EOVAP: Early-onset ventilator-associated pneumonia; TBAS: Tracheobronchial aspiration; BMI: Body mass index; APACHE II: Acute Physiology and Chronic Health Evaluation „; GCS: Glasgow Coma Scale/Score; MDRB: Multidrug-resistant bacteria; ALB: albumin; CRP: C-reactive protein; PCT: Procalcitonin; ALT: Alanine aminotransferase; Scr: Serum creatinine.

\section{Acknowledgements}

We thank all of the investigators and members of the Department of Neurosurgery, Xuanwu Hospital, Capital Medical University for their efforts

\section{Authors' contributions}

GJT conceived and designed the study. NW acquired the data. GJT and LZ contributed to manuscript drafting; GJT and HJL performed the statistical analysis. XHN was responsible for the revision of the manuscript for intellectual content. All authors read and approved the final manuscript.

\section{Funding}

This research did not receive any specific grant from funding agencies in the public, commercial, or not-for-profit sectors.

\section{Availability of data and materials}

The datasets used and/or analyzed during the current study are available from the corresponding author on reasonable request.

\section{Declarations}

\section{Ethics approval and consent to participate}

Ethics approval was obtained from the Ethics Committee of Xuanwu Hospital (approval number: [2020]018). Due to the non-interventional and retrospective nature of the study, all patient data were analyzed anonymously, a waiver of informed consent was granted by the Ethics Committee of Xuanwu Hospital. All methods were carried out in accordance with relevant guidelines and regulations.

\section{Consent for publication}

Not applicable.

\section{Competing interests}

The authors declare no competing interests.

\section{Author details}

'Department of Pulmonary and Critical Care Medicine, Xuanwu Hospital Capital Medical University, No. 45 Changchun Street, Xicheng District, Beijing 10053, China. ' Department of Neurosurgery, Xuanwu Hospital, Capital Medical University, China International Neuroscience Institute (China-INI), No. 45 Changchun Street, Xicheng District, Beijing 10053, China. ${ }^{3}$ Department of Evidence-Based Medicine, Xuanwu Hospital Capital Medical University, Beijing 100053, China.

Received: 1 February 2021 Accepted: 11 January 2022

Published online: 20 January 2022

\section{References}

1. Burja S, Belec T, Bizjak N, Mori J, Markota A, Sinkovič A. Efficacy of a bundle approach in preventing the incidence of ventilator associated pneumonia (VAP). Bosnian J Basic Med Sci. 2018;18(1):105-9.

2. Dahyot-Fizelier C, Frasca D, Lasocki S, Asehnoune K, Balayn D, Guerin AL, Perrigault PF, Geeraerts T, Seguin P, Rozec B, et al. Prevention of early ventilation-acquired pneumonia (VAP) in comatose brain-injured patients by a single dose of ceftriaxone: PROPHY-VAP study protocol, a multicentre, randomised, double-blind, placebo-controlled trial. BMJ Open. 2018;8(10):e021488.

3. Metersky ML, Wang Y, Klompas M, Eckenrode S, Bakullari A, Eldridge N. Trend in ventilator-associated pneumonia rates between 2005 and 2013. JAMA. 2016:316(22):2427-9.

4. Wang Y, Eldridge N, Metersky ML, Verzier NR, Meehan TP, Pandolfi MM, Foody JM, Ho SY, Galusha D, Kliman RE, et al. National trends in patient safety for four common conditions, 2005-2011. N Engl J Med. 2014:370(4):341-51.

5. LiY, Liu C, Xiao W, Song T, Wang S. Incidence, risk factors, and outcomes of ventilator-associated pneumonia in traumatic brain injury: a metaanalysis. Neurocrit Care. 2020;32(1):272-85.

6. Kabak E, Hudcova J, Magyarics Z, Stulik L, Goggin M, Szijártó V, Nagy E, Stevens $C$. The utility of endotracheal aspirate bacteriology in identifying mechanically ventilated patients at risk for ventilator associated pneumonia: a single-center prospective observational study. BMC Infect Dis. 2019;19(1):756-756.

7. Melsen WG, Rovers MM, Groenwold RH, Bergmans DC, Camus C, Bauer TT, Hanisch EW, Klarin B, Koeman M, Krueger WA, et al. Attributable mortality of ventilator-associated pneumonia: a meta-analysis of individual patient data from randomised prevention studies. Lancet Infect Dis. 2013;13(8):665-71.

8. Vallés J, Peredo R, Burgueño MJ. Efficacy of single-dose antibiotic against early-onset pneumonia in comatose patients who are ventilated. Chest. 2013;143(5):1219-25.

9. Bonten MJ, Huijts SM, Bolkenbaas M, Webber C, Patterson S, Gault S, van Werkhoven CH, van Deursen AM, Sanders EA, Verheij TJ, et al. Polysaccharide conjugate vaccine against pneumococcal pneumonia in adults. $\mathrm{N}$ Engl J Med. 2015;372(12):1114-25.

10. Cinotti R, Dordonnat-Moynard A, Feuillet F, Roquilly A, Rondeau N, Lepelletier D, Caillon J, Asseray N, Blanloeil Y, Rozec B, et al. Risk factors and pathogens involved in early ventilator-acquired pneumonia in patients with severe subarachnoid hemorrhage. Eur J Clin Microbiol Infect Dis. 2014;33(5):823-30.

11. Gamberini L, Giugni A, Ranieri S, Meconi T, Coniglio C, Gordini G, Bardi T. Early-onset ventilator-associated pneumonia in severe traumatic brain injury: is there a relationship with prehospital airway management? J Emerg Med. 2019;56(6):657-65.

12. Esnault P, Nguyen C, Bordes J, D'Aranda E, Montcriol A, Contargyris C, Cotte J, Goutorbe P, Joubert C, Dagain A, et al. Early-onset ventilatorassociated pneumonia in patients with severe traumatic brain injury: incidence, risk factors, and consequences in cerebral oxygenation and outcome. Neurocrit Care. 2017;27(2):187-98.

13. Guidelines for the management of adults with hospital-acquired. ventilator-associated, and healthcare-associated pneumonia. Am J Respir Crit Care Med. 2005;171(4):388-416.

14. Jung B, Embriaco N, Roux F, Forel JM, Demory D, Allardet-Servent J, Jaber S, La Scola B, Papazian L. Microbiogical data, but not procalcitonin improve the accuracy of the clinical pulmonary infection score. Intensive Care Med. 2010;36(5):790-8

15. Kalil AC, Metersky ML, Klompas M, Muscedere J, Sweeney DA, Palmer LB, Napolitano LM, O'Grady NP, Bartlett JG, Carratalà J, et al. Management of adults with hospital-acquired and ventilator-associated pneumonia: 2016 clinical practice guidelines by the infectious diseases society of america and the american thoracic society. Clin Infect Dis. 2016;63(5):e61-111.

16. Horan TC, Andrus M, Dudeck MA. CDC/NHSN surveillance definition of health care-associated infection and criteria for specific types of infections in the acute care setting. Am J Infect Control. 2008;36(5):309-32.

17. Gandra S, Tseng KK, Arora A, Bhowmik B, Robinson ML, Panigrahi B, Laxminarayan $\mathrm{R}$, Klein $\mathrm{EY}$. The mortality burden of multidrug-resistant pathogens in india: a retrospective, observational study. Clin Infect Dis. 2019:69(4):563-70.

18. Magiorakos AP, Srinivasan A, Carey RB, Carmeli Y, Falagas ME, Giske CG, Harbarth S, Hindler JF, Kahlmeter G, Olsson-Liljequist B, et al. Multidrugresistant, extensively drug-resistant and pandrug-resistant bacteria: an international expert proposal for interim standard definitions for acquired resistance. Clin Microbiol Infect. 2012;18(3):268-81.

19. Kalanuria AA, Zai W, Mirski M. Ventilator-associated pneumonia in the ICU. Critical Care. 2014;18(2):208

20. Arayasukawat P, So-ngern A-, Reechaipichitkul W, Chumpangern W, ChuennokW: Microorganisms and clinical outcomes of early- and 
late-onset ventilator-associated pneumonia at Srinagarind Hospital, a tertiary center in Northeastern Thailand. 2020.

21. Torres A, Niederman MS, Chastre J, Ewig S, Fernandez-Vandellos P, Hanberger H, Kollef M, Bassi G, Luna CM, Martin-Loeches I, et al: International ERS/ESICM/ESCMID/ALAT guidelines for the management of hospitalacquired pneumonia and ventilator-associated pneumonia: Guidelines for the management of hospital-acquired pneumonia (HAP)/ventilatorassociated pneumonia (VAP) of the European Respiratory Society (ERS), European Society of Intensive Care Medicine (ESICM), European Society of Clinical Microbiology and Infectious Diseases (ESCMID) and Asociación Latinoamericana del Tórax (ALAT). Eur Respir J 2017, 50:3.

22. American Thoracic S. Infectious diseases society of a: guidelines for the management of adults with hospital-acquired, ventilator-associated, and healthcare-associated pneumonia. Am J Respir Crit Care Med. 2005;171(4):388-416.

23. von Eiff C, Becker K, Machka K, Stammer H, Peters G. Nasal carriage as a source of Staphylococcus aureus bacteremia. New Engl J Med. 2001;344(1):11-6.

24. Blot S, Koulenti D, Dimopoulos G, Martin C, Komnos A, Krueger WA, Spina G, Armaganidis A, Rello J. Prevalence, risk factors, and mortality for ventilator-associated pneumonia in middle-aged, old, and very old critically ill patients*. Critical care Med. 2014;42(3):601-9.

25. Perbet S, Mongardon N, Dumas F, Bruel C, Lemiale V, Mourvillier B, Carli P, Varenne O, Mira JP, Wolff M, et al. Early-onset pneumonia after cardiac arrest: characteristics, risk factors and influence on prognosis. Am J Respir Crit Care Med. 2011;184(9):1048-54.

26. Polderman KH. Induced hypothermia and fever control for prevention and treatment of neurological injuries. Lancet (London, England). 2008;371(9628):1955-69.

27. Bro-Jeppesen J, Kjaergaard J, Wanscher M, Nielsen N, Friberg H, Bjerre $\mathrm{M}$, Hassager $\mathrm{C}$. The inflammatory response after out-of-hospital cardiac arrest is not modified by targeted temperature management at $33^{\circ} \mathrm{C}$ or $36^{\circ} \mathrm{C}$. Resuscitation. 2014;85(11):1480-7.

28. Dufner MC, Andre F, Stiepak J, Zelniker T, Chorianopoulos E, Preusch M, Katus HA, Leuschner F. Therapeutic hypothermia impacts leukocyte kinetics after cardiac arrest. Cardiovasc Diagn Ther. 2016;6(3):199-207.

29. Nielsen AK, Jeppesen AN, Kirkegaard H, Hvas AM. Changes in coagulation during therapeutic hypothermia in cardiac arrest patients. Resuscitation. 2016;98:85-90.

30. Kim HJ, Park KN, Kim SH, Lee BK, Oh SH, Jeung KW, Cho IS, Youn CS. Time course of platelet counts in relation to the neurologic outcome in patients undergoing targeted temperature management after cardiac arrest. Resuscitation. 2019;140:113-9.

31. Van Poucke S, Stevens K, Marcus AE, Lancé M. Hypothermia: effects on platelet function and hemostasis. Thrombosis J. 2014;12(1):31.

32. Van Poucke S, Stevens K, Kicken C, Simons A, Marcus A, Lancé M. Platelet function during hypothermia in experimental mock circulation. Artif Organs. 2016;40(3):288-93.

\section{Publisher's Note}

Springer Nature remains neutral with regard to jurisdictional claims in published maps and institutional affiliations.

Ready to submit your research? Choose BMC and benefit from:

- fast, convenient online submission

- thorough peer review by experienced researchers in your field

- rapid publication on acceptance

- support for research data, including large and complex data types

- gold Open Access which fosters wider collaboration and increased citations

- maximum visibility for your research: over 100M website views per year

At BMC, research is always in progress.

Learn more biomedcentral.com/submissions 